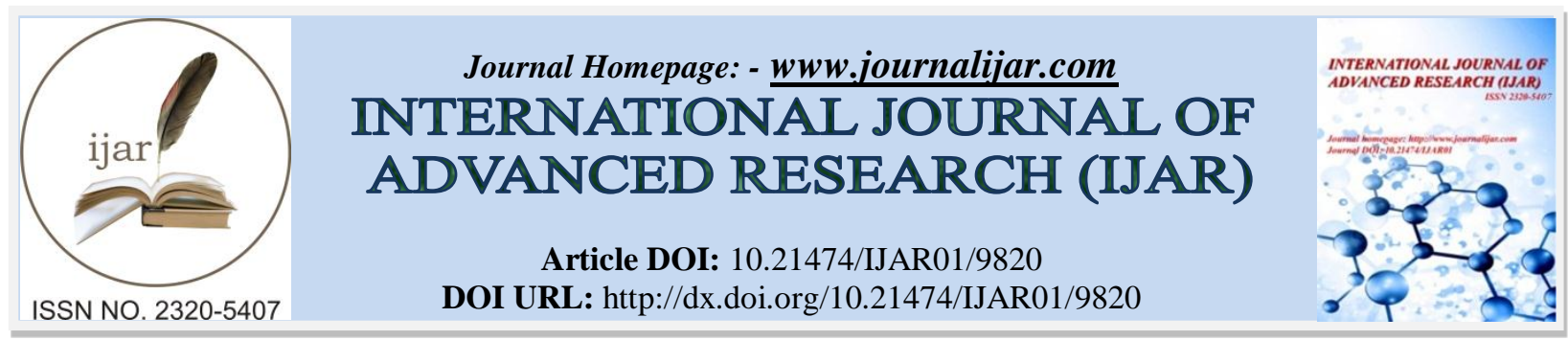

RESEARCH ARTICLE

\title{
ANALYSIS OF SOCIO-ECONOMIC FACTORS ON THE PURCHASE DECISION OF THREE- WHEELER CUSTOMERS.
}

Kapila Senavirathna ${ }^{1}$ and Prabu Premkumar ${ }^{2}$.

1. Postgraduate Department, International College of Business and Technology, Kandy, Sri Lanka.

2. Faculty of IT and Sciences, International College of Business and Technology, Colombo, Sri Lanka.

\section{Manuscript Info}

Manuscript History

Received: 06 August 2019

Final Accepted: 08 September 2019

Published: October 2019

Key words:-

Three-Wheeler, Purchase decision,

Socio-economic factors.

\begin{abstract}
Transport is one of the challenging problems for the general public of Sri Lanka. Due to the failure of meeting public transport needs by bus and railway systems, Three-Wheelers considered as an alternative transport mode of rural and urban areas since the late 1980s. As a result of that more people drive Three-Wheeler as their primary source of income. However, there is a steep reduction in purchases of ThreeWheelers in the last eight years. The objective of this research is to identify the relationship between socio-economic factors and purchase decision of Three-Wheelers. The study analyzed the relationship between personal factors, family background, the standard of living, cost factors and the financial help on the purchase decisions of ThreeWheelers. It was revealed that all the selected factors have positive relationships with the purchase decisions of Three-Wheelers. Out of all the factors, financial help and personal factors have the most significant relationship with the purchase decisions of the customers.
\end{abstract}

Copy Right, IJAR, 2019,. All rights reserved.

\section{Introduction:-}

Issues of public transport methods lead to increment and formation of Informal Public Transport (IPT) modes. Urbanization, industrial development and population lead to an increment of demand for urban transport services. Therefore, people try to find out affordable public transport even it is not much comfort to them (Hilling, 1996). Informal Public Transport (IPT) modes are widespread in Sri Lanka. Three-Wheelers are one of the most commonly used and visible IPT modes in the country. Three-Wheelers are identified as primary IPT mode of a country.

Three-Wheelers were introduced as transport service in Sri Lanka during the late 1980s and early 1990s. As of Central Bank Report (2008), it was estimated as 342,286 Three-Wheelers in the year 2007 as of the counts of initially registered vehicles of Commission of Motor Traffic (CMT). Three-Wheeler number was increased to 290,954 in 2006 from 250,822 in 2005 as by the information of Central Bank Reports (2007). Due to failure of meeting public transport needs by bus and rail system, Three-Wheelers served the transport needs of rural and urban areas as IPT service (Samarasinghe \& Samarakkodi,1999). As a result of that most people use the driving of a Three-Wheeler as their main income source. Also, this is a cheap transport mode in urban and rural areas. However, this is not a safe transport mode. However, there are consequences as well as advantages in using Three-Wheelers as IPT transportation mode in a developing country like Sri Lanka. This study further revealed the depth of socioeconomic condition in the use of Three-Wheelers as a transportation mode in Sri Lanka and most resent factors to attract customers to use the transportation method. 
Three-Wheelers are the most common vehicle in Sri Lanka. There were around 1,062,447 registered three-wheelers at the end of the year 2016. Further, the number of Three-Wheelers is higher than several cars $(675,982)$, motor Lorries $(319,001)$, dual-purpose vehicles $(366,831)$ and buses $(101,655)$. The growth rate of Three-Wheelers was $261 \%$ in the year 2008. The growth of cars was 177\%, dual-purpose vehicles were $187 \%$, motorcycles were $192 \%$, buses were $126 \%$ and Lorries were $121 \%$. These explained that society has been selected Three-Wheelers as the main mode of transport. The highest number of Three-Wheelers was registered under Western Province $(352,540)$, then southern province $(140,823)$, central province and Eastern Province $(1,331)$ in the year-end 2016(Central Bank of Sri Lanka, 2017).

According to the central bank reports from 2010 to 2018, it is obvious that the number of Three-Wheeler purchase of the last eight years has been reduced by about $75 \%$. Thus, there is a need to find out if there are any socioeconomic factors related to the purchase of Three-Wheelers. In addition, The Government of Sri Lanka had increased import taxes recently in past two years' time period to limit the number of uses of Three-Wheelers in Sri Lanka. As a result of that potential Three-Wheeler users reduce purchase of a Three-Wheeler (Mirror- Business online newspaper,2017). Thus, there could be an existence of problem of socio-economic factors on the purchase of Three-Wheelers.

The objectives of the study are:

1. To evaluate the relationship between personal factors and purchase decision of Three-Wheeler customers.

2. To evaluate the relationship between family environment and purchase decision of Three-Wheeler customers.

3. To evaluate the relationship between standard of living and purchase decision of Three-Wheeler customers.

4. To evaluate the relationship between cost factors and purchase decision of Three-Wheeler customers.

5. To evaluate the relationship between financial help and purchase decision of Three-Wheeler customers.

This study gained several benefits to several parties who sell Three-Wheelers, who purchase Three-Wheelers and several other interested readers. Research findings help to identify the ways that people adopted to buy ThreeWheelers and trend of purchasing Three-Wheelers. Three-Wheeler selling companies can use proper selling strategies and techniques to enhance the purchase of Three-Wheelers based on the research findings. Since there are literature and the theoretical gap in this research area, this study provides a contribution to fill the gap. It is not practical to collect data from such a large population. Therefore, the researcher had to limit the data collected from people who had Three-Wheelers and live in Colombo district. Hence, the accessibility issue is one of the limitations of the research study. Further, the sample size is also insignificant when compared to people who own ThreeWheelers in the country. Thus, sampling error is also a limitation in the study. The survey questionnaire is translated to Sinhala and questioned from the three-wheel owners. Some people don't have writing and reading skills. Also, some might understand the question in the wrong way. All these language-related limitations are also caused significant limitations of the study. Several other factors influence to purchase Three-Wheelers for people other than socio-economic factors. Those are not taken into consideration in the study. This is also another research limitation of the research study.

\section{Review of Literature: - Purchase Decision}

Consumer purchase decision-making procedure can sometimes be a complex process and consumers can rely on the information about specific products and brands and their consumer experience gathered to reach purchase decision (Jiang \& Rosenbloom, 2005). Operationally purchase decision of consumer has five stages of decision making, that is problem recognition, information gathering, evaluate alternatives, make purchase decisions, and post-purchase behaviour. The purchasing process is started much ahead of purchase and its consequences remain for a significant period after purchase.

\section{Socio-Economic Factors}

As for the study of Kumarage et al (2010), it was found out social exclusions, social stigma and government enforcements are main challenges faced by Three-Wheeler drivers. However, in this study, it is considered about the social factors influencing on purchase a three-wheeler. Kumarage et al (2010) similarly found the relationship between income level and job satisfaction of Three-Wheeler drivers. Fuel cost is also higher to three-wheeler drivers. Also, this research found out the influence of financial help to purchase a Three-Wheeler. Moreover, the paper found issues created from Three-Wheelers from being an unregulated public transport mode. Likewise, it was found out people hire a three-wheeler and become Three-Wheel drivers' due to unemployment. Further, the paper 
expressed about the informality of the transportation method of Three-Wheelers in the country. This paper is also focused on the influence of unregulated aspect of Three-Wheeler on the reduction on the social status of a ThreeWheeler driver.

These Socio-economic factors may be influencing every middle-class consumer to demand a Three-Wheeler. These factors can be explained as follows,

\section{Personal Factor}

People want to enhance their comforts and convenience in developing society. Hence, people expect a comfortable and convenient journey. Hence, people go for a personal vehicle. Sri Lanka is a country which has a broader range of middle-class people and they always try to live in convenience as far as possible. Concerning that, most of the people who lived in the middle class are employed people who normally living according to their monthly salary. Most of the time they don't have an extra way to find money and then they normally used to manage the monthly salary to fulfil the needs of the family. Since the people in Sri Lanka are more towards cultural oriented, they always need to stay with the family members, and they have bonded with the members of the family. So, they have identified Three-Wheeler are a small, convenient and simple way of travelling with their loved ones for the loved places. According to research (Samarakon et.al., 2018), 64\% of Three-Wheeler drivers' education was limited to Ordinary Level qualifications. A surprising amount of $46 \%$ claimed a daily income of only Rs. 500-1,000. Further, $33 \%$ of the Three-Wheeler drivers, received a monthly income of Rs. 20,000-30,000.

\section{Quick Travelling Factor}

Everyone wants to reach his destination without any delay. Besides, they expect a comfortable journey. These types of aspects are not obtained in public transport or hiring vehicle. The three-wheeler provides these facilities (Aworemi et.al, 2008). In present, there can be seen huge traffic on the roads. Although there are many sub roads to reach the required destinations, public transport doesn't normally go from those roads. So, people are looking for ways and means to reach for the required destinations easily and quick as far as possible, therefore. they need to have small vehicles on their own. Consequently, they are tending to purchase Three-Wheelers as it will help to reach their required destinations more quickly with the lowest cost. At the same time, Three-Wheelers can go forward in any traffic as it is a small vehicle, and this will also make the travelling experience of the people quicker and more convenient.

\section{Family Norm}

Two adults can easily travel in a Three-Wheeler. The middle-class consumers accept norms which can use a ThreeWheeler to move from one place to another. Normally the middle-class people travel for their working places, relative homes and sacred places. In that, they love to go with their family members. In that manner, they have identified the Three-Wheeler as the best way to fulfil their travelling needs more conveniently and quickly. Majority of Three-Wheeler drivers are married, and their wives stay at home and some of them do not engage any income sources (Samarakon et.al., 2018).

\section{Inadequacy of the Public Transport System}

The transport is vital in the development of a country There are some villages in this country without a public transport facility. Even if there is public transport, the service does not provide the expected convenience to the people. The people used to spend time waiting for public transport. To avoid inconvenience as well as a wasting of time, people use Three-Wheeler of their own to undertake travel. The needs want and the expectations of the people are changing day by day. They need more resources to fulfil their needs and in that so, they are trying to fulfil their needs with the managed resources. To fulfil the dynamic travelling needs, the public transport system is not enough and in addition to that, the general public tends to look for new ways and means of alternative travel options (Kumarage et.al.,2010). When considering the alternative travel options Three-Wheelers are considered as one of the best modes of travels where a family can easily travel within it.

\section{Convenient Factor}

Transport becomes convenient and cheaper by having owned a Three-Wheeler to travel to the nearby locality. Sri Lanka is a country in which has a value system and thereby people tend to make collective decisions and try to survive from the family's own decision. As they wanted to take collective decisions, they always try to implement the decisions collectively. The purpose of purchasing a vehicle is the convenience of travelling. When it comes to 
the middle class, they couldn't purchase big vehicles due to the financial constraints and that tend to purchase ThreeWheelers for their own (Kumarage et.al., 2010).

\section{Cost Factor}

Three-Wheeler is less priced when comparing the cost with others. The middle-class consumer prefers for ThreeWheeler. Cost also influences on the demand of Three-Wheeler (Raje, 2004). In that, although they wanted to have a better motor vehicle, they couldn't afford because of the financial constraint. As a result of that, they tend to move for the Three-Wheelers on a lease basis. Most of the time, there's a huge potential to purchase second-hand vehicles as it normally costs at the lowest rate.

\section{Standard of Living}

Income is one of the major factors which decides the standard of living of people. Most of the potential ThreeWheeler customers are unskilled and do several jobs. They are daily paid people since there is no guaranteed income per month. It was found out they are mainly daily income earners reported to earn Rs 750 and profit makes it around Rs 136.50. Also, their expenditure is around Rs 613.50. Standard of living of people influenced the purchase decision of a Three-Wheeler (Kalegama and Mukherji, 2007).

\section{Financial Help}

Financial help is important to buy vehicles because people usually can't afford high price to buy vehicles at once. Therefore, financial institutions provide leasing facilities and several other vehicle loans to make people purchase vehicles in a more convenient manner (Kalegama and Mukherji, 2007).

\section{Methodology:-}

The conceptual model was derived from the findings of previous studies.

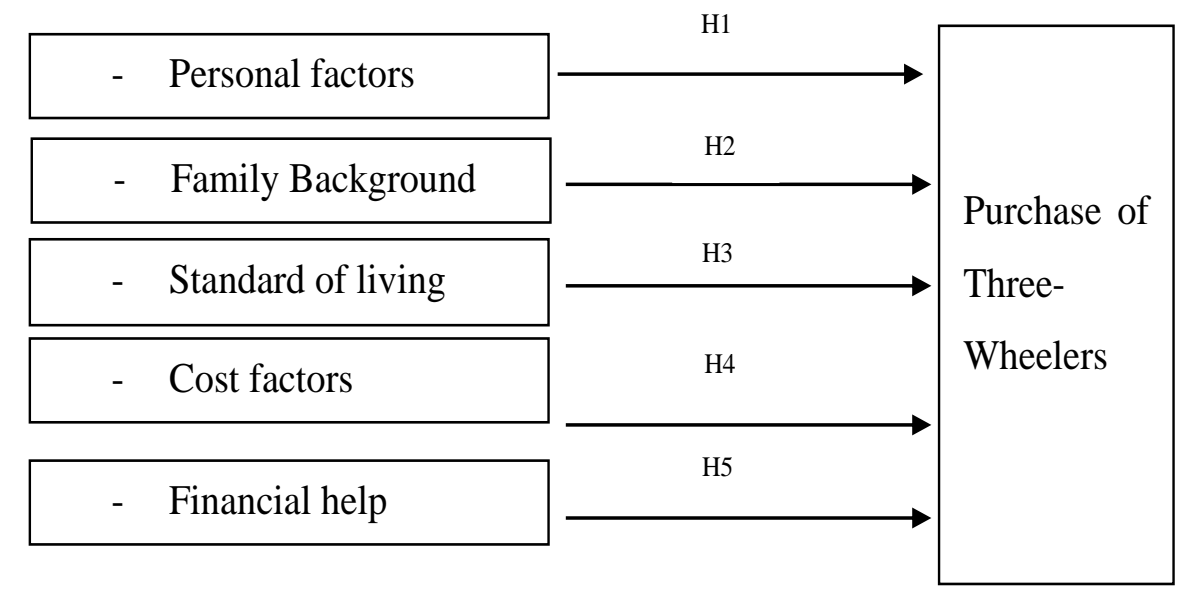

Figure 2:-Conceptual Model

\section{Development of Hypotheses}

Following are the Hypotheses developed for the research study.

H1: $\quad$ There is a relationship between Personal factors and purchase decisions of Three-Wheelers.

H2: $\quad$ There is a relationship between Family background of a person and purchase decision of Three-Wheelers.

H3: $\quad$ There is a relationship between the Standard of living and purchase decisions of Three-Wheelers.

H4: There is a relationship between Cost factors and purchase decisions of Three-Wheelers.

H5: $\quad$ There is a relationship between Financial help and purchase decisions of Three-Wheelers.

\section{Research Design}

This study takes a deductive research approach to achieve the objectives of the study because this is used the existing theories and practices to certain phenomena to test and thereby to give conclusions and recommendations.

\section{Population and Sampling}

The population consists of customers who bought Three-Wheeler within the last 12 months that is about 20,000 . Considering $95 \%$ confidence level and confidence level of 5, the sample size is 377 . However, 500 respondents 
were selected from the population. A convenient sampling method is used to collect data for the study. The sample is taken only from the Three-Wheeler owners within Colombo district.

\section{Data collection methods}

Primary data sources are the type of data which is collected only for the study purpose. Those data and the information are very important for study purpose. A self-administered questionnaire was used as the main instrument of data collection. The study was conducted in a non-contrived setting, which is neutral with less interference. Since the data were collected from the general public.

The questionnaire was comprised of 2 sections. Section I consisted of demographic attributes (age, gender, department etc.). Sections 2 related to personal factors, family background, the standard of living, cost factors and the financial help, and purchase decisions. The respondents were asked to indicate their perception on a 5- point Likert scale ranging from "strongly disagree" 1 to "strongly agree" 5 . The reliability of the questionnaire was measured through Cronbach's Alpha coefficients. The values of coefficient ranging are above 0.7 for all the variables, considered to be relatively high and internally consistent. The data were analyzed by using descriptive statistics and inferential data analysis methods; this was done with the aid of Statistical Package for Social Science (SPSS).

\section{Data Presentation and Analysis: -}

Majority of the respondents of the questionnaire were male (98\%) and aged between $18-35$. Also, it is noted that the majority of them owns a Three-Wheeler for less than three years. Further most of them use Three-Wheeler for hiring purpose. About $25 \%$ of the respondents are Three-Wheeler drivers while $13 \%$ of them are self-employed technicians. More than $80 \%$ of the respondents are earning less than Rs 35000 per month.

\section{Descriptive Statistics on Independent Variables}

The frequency analysis was used to analyses the attributes of the independent variables and the findings shows that more than $50 \%$ of the respondents are on agreeing or strongly agreeing on the following statements related personal factors, family background, the standard of living, cost factors, and financial help related to three-wheeler customer.

1. About $69.2 \%$ of the respondents believe Three-Wheeler is in line with their social status

2. According to $69.6 \%$ of customers, Three-Wheeler is convenient for their age and education level.

3. The Three-Wheeler is the main income source for $72.6 \%$ of respondents.

4. Three-Wheeler as the most convenient transport method of their family for $74.4 \%$ of customers

5. According to $69.4 \%$ of customers, Three-Wheelers helped to avoid all consequences happened from motorcycle and facilities similar to a car.

6. About $70.2 \%$ of customers' feel Three-Wheeler satisfy the transport needs of their family and themselves.

7. $71.6 \%$ of customers were comfortable to use Three-Wheeler for family condition.

8. A significant amount of respondent's $(71.8 \%)$ uses Three-Wheeler because they match with the middle-class living conditions.

9. $70.8 \%$ of customers feel it is affordable to maintain Three-Wheeler considering their income level.

10. $73.8 \%$ of customers bear the loan cost of Three-Wheeler because it was hard to bear more than that amount to purchase another type of vehicle.

11. About $72.2 \%$ of customers feel the transportation cost of the family reduced due to Three-Wheeler.

12. $69.2 \%$ of customers agreed that leasing helped to buy Three-Wheeler because their income level was not enough to buy Three-Wheeler.

13. $71 \%$ of customers received help from their employer to buy Three-Wheeler.

\section{Hypotheses Testing}

The Pearson bivariate correlation was used to analyses the relationship between independent and dependent variables at 0.05 significant levels.

Table 1:-Hypothesis testing using correlation analysis

\begin{tabular}{|l|l|l|l|}
\hline Hypothesis & Pearson Correlation & $\operatorname{Sig}(2$ tailed $)$ at 0.05 & Results \\
\hline H1 & 0.603 & 0.000 & Supported \\
\hline H2 & 0.565 & 0.000 & Supported \\
\hline H3 & 0.520 & 0.000 & Supported \\
\hline H4 & 0.556 & 0.000 & Supported \\
\hline
\end{tabular}




\begin{tabular}{|l|l|l|l}
\hline H5 & 0.638 & 0.000 & Supported
\end{tabular}

According to the statistical findings, all the Hypothesis are supported. The H1 and H5 are comparatively more significantly related to the dependent variable. Therefore, we can conclude that personal factors, family background, the standard of living, cost factors, and financial help have a positive and moderate relationship with purchase decisions of Three-Wheeler customers. Further personal factors and financial help are comparatively more significant in the purchase decision of the customer.

\section{Conclusion:-}

\section{Socio-economic factors, associate with the users of Three-Wheelers}

The research findings show that the selected socio-economic factors have a positive relationship with the purchase decision of Three-Wheeler customers. Most customers were happy about the usage of the Three-Wheeler because it represented their social status. Three-Wheeler is affordable to most of the customers who purchased Three-Wheelers within last year. They are convenient to use, and it is matched with their education level/age. Three-Wheeler is identified as the most convenient transport method for the family. It is comfortable to travel under present family conditions. Three-Wheeler is matched with the middle-class living conditions of most customers. Three-Wheeler maintenance cost is affordable to users because it is in line with their income level. Loan cost of the Three-Wheeler is bearable to customers because they are unable to bear the huge cost to buy another vehicle like car, van, etc. Customers prefer to use leasing facility to purchase a Three-Wheeler. There are instances employers helped to buy the Three-Wheeler and paid in instalment basis.

The research concludes that socio-economic factors such as personal factors, family background, standard of living, cost factors, and financial help positively influence purchase decisions of Three-Wheeler customers and these findings are very similar to the findings of the previous research studies.

\section{Recommendations}

The possible reduction import duties, enhance social status of Three-Wheeler drivers, increase leasing facility, arrange instalment payment plans by financial institutions may improve the purchasing of Three-Wheelers. Threewheeler companies must consider the socio-economic factors of potential customers when planning marketing strategies to sell Three-Wheelers.

\section{Further Research: -}

This topic can be slightly changed for studies in the future such as investigate the reasons for the increment of illegal activities of Three-Wheeler drivers (Nonis,2003), factors cause to increase the purchase of Three-Wheelers in the country etc. However, the findings of this study will be helpful to conduct future studies.

\section{References:-}

1. Aworemi, J.R., Salami, A.O., Adewoye, J.O., \&Iiori, M.O. (2008). Impact of socioeconomic characteristics on formal and informal public transport demands in Kwara state, Nigeria.Journal of Business Management, 2(4).

2. Central Bank of Sri Lanka. (2007). Economic and Social Statistics of Sri Lanka. Statistics Department, Colombo.

3. Central Bank of Sri Lanka. (2008). Economic and Social Statistics of Sri Lanka. Statistics Department, Colombo.

4. Central Bank of Sri Lanka. (2017). Economic and Social Statistics of Sri Lanka. Statistics Department, Colombo.

5. Hilling, D. (1996). Intermediate Public Transport. Transport and Developing Countries. Routledge, New York, pp. $212-225$

6. Jiang, Pingjun., Rosenbloom, Bert. (2005). Customer intention to return online: price perception, attribute-level performance, and satisfaction unfolding over time. European Journal of Marketing, 39(1/2), $150-174$.

7. Kalegama, S., \& Mukherji, I. (2007). Indo-Sri Lanka Bilateral Trading Agreement: Six Years Performance and Beyond. Research and Information Systems for Developing Countries, NewDeli

8. Kumarage, A. S., Bandara, M., \& Munasinghe, D. (2010). Analysis of the economic and social parameters of the Three-Wheeler Taxi service. Elsevier, 395-400 
9. Mirror- Business online newspaper. (2017). Three-wheeler registrations slump as new leasing levels come into effect(Online). Available from: http://www.dailymirror.lk/article/Three-wheeler-registrations-slump-as-newleasing-levels-come-into-effect--122740.html [Accessed on 2/25/2018]

10. Nonis, A. (2003). Crimes on Wheels.Sunday Observer(Online).Available from: http://www.sundayobserver.lk/2003/03/02/fea10.html - 54 - [Accessed on 2/1/2018]

11. Raje, F. (2004). Transport Demand Management and Social Inclusion: The need for Ethnic Perspective, Ashgate, England.

12. Samarasinghe, T.A, \& Samarakkodi, N. C. (1999). A Study on the Operation of Three-Wheelers in Sri Lanka (Final year Thesis). Department of Civil Engineering. The University of Moratuwa.

13. Samarakoon, M.T., Wijewardhana, B.V.N. and Shayamali, W.M.W. (2018). A sociological study of the socioeconomic background of three-wheel drivers in rural Sri Lanka: Special reference to Rathnapura, Ambilipitiya and Wallavaya areas. International Journal of Academic Research and Development,3(1), 659-662. 